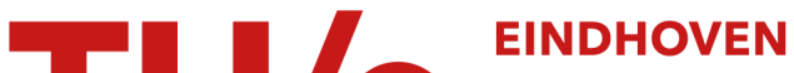 UNIVERSITY OF TECHNOLOGY
}

\section{Once-through contactless flow boiling in a micro evaporator}

\section{Citation for published version (APA):}

Rops, C. M., Oosterbaan, G. J., \& Geld, van der, C. W. M. (2014). Once-through contactless flow boiling in a micro evaporator. Interfacial Phenomena and Heat Transfer, 2(3), 265-271.

https://doi.org/10.1615/InterfacPhenomHeatTransfer.2015011652

DOI:

10.1615/InterfacPhenomHeatTransfer.2015011652

Document status and date:

Published: 01/01/2014

\section{Document Version:}

Publisher's PDF, also known as Version of Record (includes final page, issue and volume numbers)

\section{Please check the document version of this publication:}

- A submitted manuscript is the version of the article upon submission and before peer-review. There can be important differences between the submitted version and the official published version of record. People interested in the research are advised to contact the author for the final version of the publication, or visit the $\mathrm{DOI}$ to the publisher's website.

- The final author version and the galley proof are versions of the publication after peer review.

- The final published version features the final layout of the paper including the volume, issue and page numbers.

Link to publication

\section{General rights}

Copyright and moral rights for the publications made accessible in the public portal are retained by the authors and/or other copyright owners and it is a condition of accessing publications that users recognise and abide by the legal requirements associated with these rights.

- Users may download and print one copy of any publication from the public portal for the purpose of private study or research.

- You may not further distribute the material or use it for any profit-making activity or commercial gain

- You may freely distribute the URL identifying the publication in the public portal.

If the publication is distributed under the terms of Article 25fa of the Dutch Copyright Act, indicated by the "Taverne" license above, please follow below link for the End User Agreement:

www.tue.nl/taverne

Take down policy

If you believe that this document breaches copyright please contact us at:

openaccess@tue.nl

providing details and we will investigate your claim. 


\title{
ONCE-THROUGH CONTACTLESS FLOW BOILING IN A MICRO EVAPORATOR
}

\author{
C. M. Rops, ${ }^{1, *}$ G. J. Oosterbaan, ${ }^{2}$ \& C. W. M. van de Geld ${ }^{2}$ \\ ${ }^{1}$ TNO, De Rondom 1, 5612 AP Eindhoven, The Netherlands \\ ${ }^{2}$ Eindhoven University of Technology, PO Box 513, 5600 MB Eindhoven, The Netherlands \\ *Address all correspondence to C. M. Rops, E-mail: cor.rops@tno.nl
}

Equipment miniaturization offers several opportunities such as an increased surface-to-volume ratio combined with high heat transfer coefficients. However, moving toward small-diameter channels demands extra attention to fouling, reliability, and stable operation of the system. The present investigation explores the possibilities of hot gas flow through the porous wall of a pipe as a means to evaporate a liquid fully flowing in the pipe. A reduction of the pressure fluctuations of about $30 \%$ to $40 \%$ is obtained with this so-called contactless boiling. Because of the injected gas, wall temperatures measured are higher. The reduction in heat transfer coefficient corresponds to an insulating gas layer at the wall with an estimated thickness of $20 \mu \mathrm{m}$.

KEY WORDS: flow boiling, heat transfer, inverted annular flow

\section{INTRODUCTION}

A fascinating progress has been made in the miniaturization of micro evaporators during the last decades. A decrease in channel diameter leads to an increased surface-to-volume ratio and high heat transfer coefficients. Miniaturization leads to disposable and/or lightweight equipment. Recent evaporator designs contain a large number of mini and micro channels (Rops et al., 2008).

However, small channel diameters demand extra care on fouling, reliability, and thermo-mechanical management. Additionally, the maximum achievable heat flux is limited by various physical processes. For instance, the pressure drop over a micro channel increases rapidly with decreasing channel diameter. The importance of body forces like gravity and inertia is less than the capillary forces which cause an increased probability of channel blockage (Rops et al., 2008). Even explosive vapor bubble growth is observed (Zhang et al., 2005), which induces large pressure fluctuations (Kennedy et al., 2000) and flow instabilities (Kandlikar, 2004).

Fouling and reliability of a micro system are obviously determined by the deposition and entrainment rates of particles at the wall. In addition, the heated wall of the micro evaporator may act as a catalyst leading to fouling accumulation undesired reactions. This may lead to uncontrolled behavior of the micro evaporator over time (Perry, 2008). A novel strategy to reduce the fouling and enhance the system stability is the creation of a thin gas blanket between the wall and the fluid. The flow pattern thus created resembles so-called inverted annular flow. Film boiling in heated tubes may give a vapor film at the wall with a liquid core in the center of the channel (Nakla et al., 2011). In regular sized pipes ( $20 \mathrm{~mm}$ diameter) with a hydrophobic wall, Takamasa et al. (2008) observed such inverted flows. In micro channels, a stable inverted annular flow may occur. Huh et al. (2009) observed various inverted types of flow in air-water flows. Detailed stability analyses concerning this topic are available in literature, e.g., Yan et al. (2003). Micro channels have perimeters typically less than $1 \mathrm{~cm}$, thus smaller than the typical Taylor wavelength obtained by the Kelvin-Helmholtz instability. This may indicate that in micro channels inverted annular flow can be a stable flow pattern. 
In-depth investigations and modeling were performed concerning boiling stability inside porous media. More than two decades ago Ramesh and Torrance $(1990,1993)$ investigated boiling stability inside a boiling porous medium applying a detailed model for liquid-dominated reservoirs based on natural convection. A linear stability study explained the experimental data found by Stemmelen et al. (1992). Sahli et al. (2010) simplified and extended the model of Ramesh to a more generic two-phase stability model. Literature concerning boiling on top of a porous medium is less abundant. Generally, the porous medium is regarded as a micro-structured wall influencing the nucleate boiling properties; see Nakayama et al. (1982) and Mori and Okuyama (2009). Apart from a theoretical analysis (Shagapov and Nurislamov, 2010), no literature has been found on boiling on a porous medium through which a gas is blown to lift the liquid from the wall.

The present investigation explores possibilities to enhance the reliability and stability of a once-through micro evaporator by lifting the boiling fluid off the wall. First, it will be attempted to reduce the pressure fluctuations by varying the channel diameter along the tube. Next, it is attempted to lift the boiling liquid off the wall by feeding hot nitrogen through a porous wall. An experimental setup with exchangeable test sections is made (Section 3). Results are discussed in Section 4.

\section{THEORETICAL BACKGROUND}

In general, three different contributions to the total pressure drop in a two-phase flow system are recognized:

$$
\Delta P_{\text {tot }}=\Delta P_{\text {static }}+\Delta P_{\text {mom }}+\Delta P_{\text {fric }}
$$

where $\Delta P_{t o t}$ is the total pressure drop over the boiling channel, $\Delta P_{\text {static }}$ is the hydrostatic pressure drop induced by a height difference, $\Delta P_{\text {mom }}$ is the momentum pressure drop generated by the acceleration of the fluid, and $\Delta P_{\text {fric }}$ is the frictional pressure drop. If the ratio of the mean gas velocity to the mean liquid velocity, so-called slip velocity, inside the channel is known at each axial position, the first two pressure drops are straightforward to be estimated. The frictional contribution to the pressure drop requires more empirical input.

The momentum pressure contribution can be expressed as a function of the vapor quality and the liquid and vapor density. In the case of a continuously widening channel with an inlet diameter, $D_{i}$, and an outlet diameter, $D_{o}=\alpha D_{i}$, and assuming a complete transition from single-phase liquid to single-phase vapor, the simplified momentum pressure drop becomes (Rops et al., 2008)

$$
\Delta P_{\text {mom }}=\left[\frac{m_{\text {tot }}^{2}}{2 \alpha^{4} \frac{\pi^{2}}{16} D_{i}^{4} \rho_{\text {gas }}}-\frac{m_{\text {tot }}^{2}}{2 \frac{\pi^{2}}{16} D_{i}^{4} \rho_{\text {liq }}}\right]=\frac{G_{\text {tot }, i}^{2}}{2}\left[\frac{1}{\alpha^{4} \rho_{\text {gas }}}-\frac{1}{\rho_{\text {liq }}}\right]
$$

where $m_{\text {tot }}$ is the total mass flow rate, in $\mathrm{kg} / \mathrm{s}$, through the widening channel and $\alpha$ is the ratio of the outflow diameter, $D_{o}$, over the inlet diameter, $D_{i}$ and $G_{t o t, i}$ is the mass flux at the inlet in $\mathrm{kg} / \mathrm{m}^{2} \mathrm{~s}$. Next, $\rho_{\text {gas }}$ is the vapor density, $\rho_{\text {liquid }}$ the liquid density.

To estimate the two-phase friction pressure drop, various empirical models have been proposed in literature. However, the general idea is often to calculate a single-phase pressure drop and apply some two-phase multiplier to obtain the two-phase frictional pressure drop component. Rops et al. (2014) have shown a simplified general expression for the frictional component of the pressure drop for a widening channel, assuming a complete transition from singlephase liquid to single-phase vapor:

$$
\Delta P=\frac{\text { const } \cdot L}{D_{i}^{4}} \cdot \frac{-1}{3}\left(\frac{1-\alpha^{-3}}{1-\alpha}\right)
$$

Using again $D_{o}=\alpha D_{i}$, the constant, const, comprises model specific parameters used for the two-phase multiplier such as the vapor quality and the Martinelli constant. For reasons of simplicity in the derivation all these parameters are regarded not to be dependent on the channel widening, $\alpha$.

Equations (2) and (3) show that the pressure drop for a widening channel is reduced as a function of the ratio of the exit and entry diameter. Rops et al. (2014) shows that the momentum pressure drop is reduced by more than a factor 
of 10 for diameter ratios larger than 2 . The frictional pressure drop is reduced to less than $30 \%$. Hence, in a conical channel the two-phase flow will be much less violent than in a constant diameter channel. Similar observations can be found in the work of Mukherjee and Kandlikar (2005). Therefore a conical channel is regarded to be more suitable to sustain a gas bearing near the wall.

The heat transfer from the outside heater through the wall is by conduction. With measured temperature profiles in the radial direction the heat flux through the wall into the boiling fluid is estimated from

$$
q_{r}=\lambda \frac{T_{1}-T_{2}}{r \ln \left(r_{1} / r_{2}\right)}
$$

where $q_{r}$, in $\mathrm{W} / \mathrm{m}^{2}$, is the heat flux in the radial direction at the radial location $r$. Next, $\lambda$, in $\mathrm{W} / \mathrm{m} \mathrm{K}$, is the thermal conductivity, $T_{1}$ and $T_{2}$ are the temperatures on radial location 1 and 2 . The radial temperature profile is given by

$$
T(r)=\frac{T_{1}-T_{2}}{\ln \left(r_{1} / r_{2}\right)} \ln \left(r / r_{2}\right)+T_{2}
$$

The heat transfer coefficient, $h$ in $\mathrm{W} / \mathrm{m}^{2} \mathrm{~K}$, is calculated by dividing the heat flux by the temperature difference. For the boiling heat transfer coefficient the extrapolated wall (solid-fluid interface) heat flux and temperature are used. The bulk fluid temperature is assumed to be at saturation temperature: i.e., $100^{\circ} \mathrm{C}$ for near-atmospheric conditions.

The heat resistance is defined as the inverse heat transfer coefficient, $R_{t h}=1 / h$. The total heat resistance is an addition of the separate heat resistances. Thus the total heat transfer coefficient can be calculated by $1 / h_{\text {total }}=\Sigma 1 / h_{n}$. If a gas layer would be present in the porous boiling channel, an additional heat resistance would be formed on top of the boiling heat transfer coefficient. For example, a 10 micrometer thick nitrogen layer has a thermal resistance, $R_{t h}$, of about $3 \times 10^{-4} \mathrm{~m}^{2} \mathrm{~K} / \mathrm{W}$. Therefore the total heat transfer coefficient from the wall to the boiling liquid cannot exceed $3 \times 10^{3} \mathrm{~W} / \mathrm{m}^{2} \mathrm{~K}$ anymore, if such a layer would be present. The occurrence of a fictitious gas layer would limit the maximum heat flux to $\sim 1 \times 10^{5} \mathrm{~W} / \mathrm{m}^{2}$ if the wall superheat would amount to $\sim 30^{\circ} \mathrm{C}$. This fact will be used in the analysis below.

\section{EXPERIMENTAL SETUP}

To investigate the presence of a gas layer between the wall and the boiling fluid, three setups have been made:

1. a stainless steel channel with a constant diameter of $0.6 \mathrm{~mm}$;

2. a stainless steel conical channel: inlet diameter $0.6 \mathrm{~mm}$ and outlet diameter $3 \mathrm{~mm}$; and

3. a conical channel with a porous wall: inlet diameter $0.6 \mathrm{~mm}$ and outlet diameter $3 \mathrm{~mm}$.

All three channels have the same heated length of $50 \mathrm{~mm}$, combined with a non-heated entrance length of $14.75 \mathrm{~mm}$ from the pressure sensor up to the heated channel. In all three channels, two rows of $5 \mathrm{~K}$-type thermocouples are placed, with $0.5 \times 0.8 \mathrm{~mm}$ as outer dimensions of the sensing part. The first row is $0.8 \mathrm{~mm}$ from the boiling surface and the second row is $6.3 \mathrm{~mm}$ from the boiling surface; see Fig. 1. The total wall thickness is $8 \mathrm{~mm}$.

Demineralized water $\left(\sim 20^{\circ} \mathrm{C}\right.$ inlet $)$ flows from the flow controller past a differential pressure sensor, which measures the pressure difference between the upstream location and the ambient pressure. No special attention is given with respect to degassing the water. The measurements of the constant diameter channel are done with the Honeywell 142PC05D (Full Scale Range $=34,475 \mathrm{~Pa}$, error $= \pm 0.5 \%$ ) pressure transducer and the measurements of both conical channels are done with a Honeywell 164PC01D37 (Full Scale Range $=2492$ Pa, error $= \pm 0.5 \%$ ). This sensor is placed near the interchangeable heated channel, however still allowing the visual detection of possible backflow. Boiling starts at the heated section. The heated channel has an atmospheric outlet, which ensures that the pressure measured by the pressure sensor is the total pressure drop of the channel.

For all three measurement setups heat is supplied with a heating wire tightly spun around the outside wall. This heating wire allows the gas to pass through the wall uniformly in the case of the porous channel. The first temperature

Volume 2, Number 3, 2014 


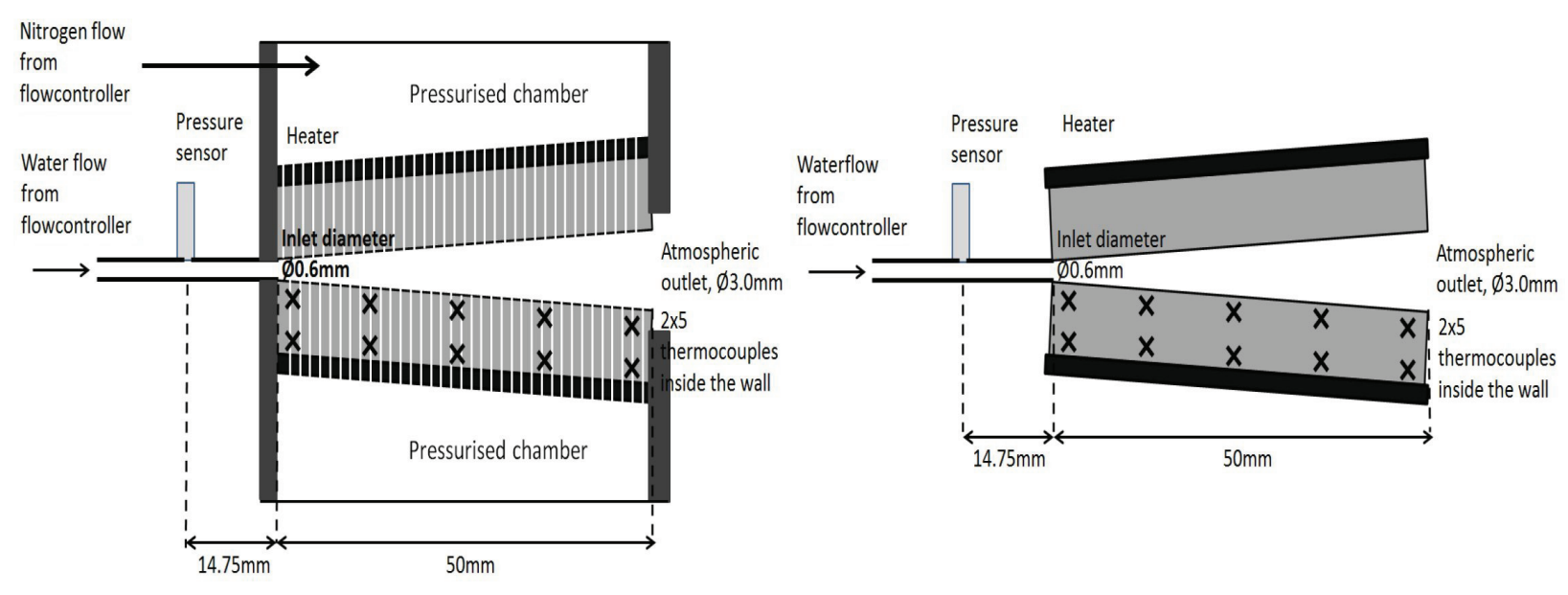

FIG. 1: Schematic drawing of the measurement setup. Left: Conical channel with porous wall to achieve contactless boiling. Right: Similar solid conical channel for comparison.

sensor is placed $4 \mathrm{~mm}$ after the inlet of the heated section and $0.8 \mathrm{~mm}$ from the channel interior wall. This temperature serves as an input for the electronic control system regulating the heat input. This temperature is kept constant during the measurement and is referred to as the wall temperature, $T_{\text {wall }}$. The water is supplied using a flow controller (brand Bronkhorst, type mini-coriflow, M12). The accuracy of the water flow controller is $0.2 \%$ of the actual value.

In order to supply the gas through the porous wall, an additional chamber is created around the heated channel. This gas tight chamber is fed by a nitrogen supply using a flow controller (Bronkhorst, type EL FLOW, F-201C). The accuracy of the nitrogen flow controller is $0.2 \%$ of the actual value plus $0.2 \mathrm{ml} / \mathrm{min}$, i.e., $0.1 \%$ full scale. The porous wall (SIKA-R 0.5AX) is made of small stainless steel particles sintered together with a typical hole size of about $0.5 \mu \mathrm{m}$ and a typical volume porosity $\sim 21 \%$. The conical channel is made by electrical discharge machining (wire EMD) in order to keep the pores open. Regular milling techniques would smear out the material and therefore create a closed wall.

The measurements have been performed using the following procedure. First the heater is turned on and the wall is brought to the desired temperature. Typically, the wall temperature is set at approximately $130^{\circ} \mathrm{C}$. For water this temperature is close to the critical heat flux temperature, which is $126^{\circ} \mathrm{C}$ for pool boiling. Next, the water is turned on and set to $1,3,5,10,15,20,30$, and $40 \mathrm{gr} / \mathrm{h}\left(1 \mathrm{gr} / \mathrm{h}=2.78 \times 10^{-10} \mathrm{~m}^{3} / \mathrm{s}\right)$. The liquid-only Reynolds number, based on the inlet diameter, is 0.6 to 25 . In the case of the experiments with gas, first a constant gas chamber pressure (10200 mbar) was set resulting in a defined nitrogen supply $(\sim 5, \sim 10, \sim 20, \sim 40, \sim 100, \sim 150 \mathrm{ml} / \mathrm{min})$ before turning on the water flow. After a system stabilizing period of about $2 \mathrm{~min}$, the pressure sensor is logged (typical read-out frequency $1 \mathrm{kHz}$ ) for at least 5-10 min.

These data are used to obtain the average pressure drop and its fluctuation level. The measurements for all three channels have been repeated, after pulling apart and reconstructing the entire measurement setup. The results did not change significantly $(<10 \%)$. Similarly, the readout frequency did not significantly affect the mean pressure drop results, nor the statistical values representing the pressure fluctuations.

\section{RESULTS AND DISCUSSION}

Figure 2 compares measured average pressure drops for various water flow rates. Reproducibility of the average pressure drop is within $10 \%$. The pressure drop over the adiabatic inlet channel between the pressure sensor and the heated part is small as compared to the total pressure drop: at $40 \mathrm{gr} / \mathrm{h}$ this pressure drop is about $50 \mathrm{~Pa}$. 


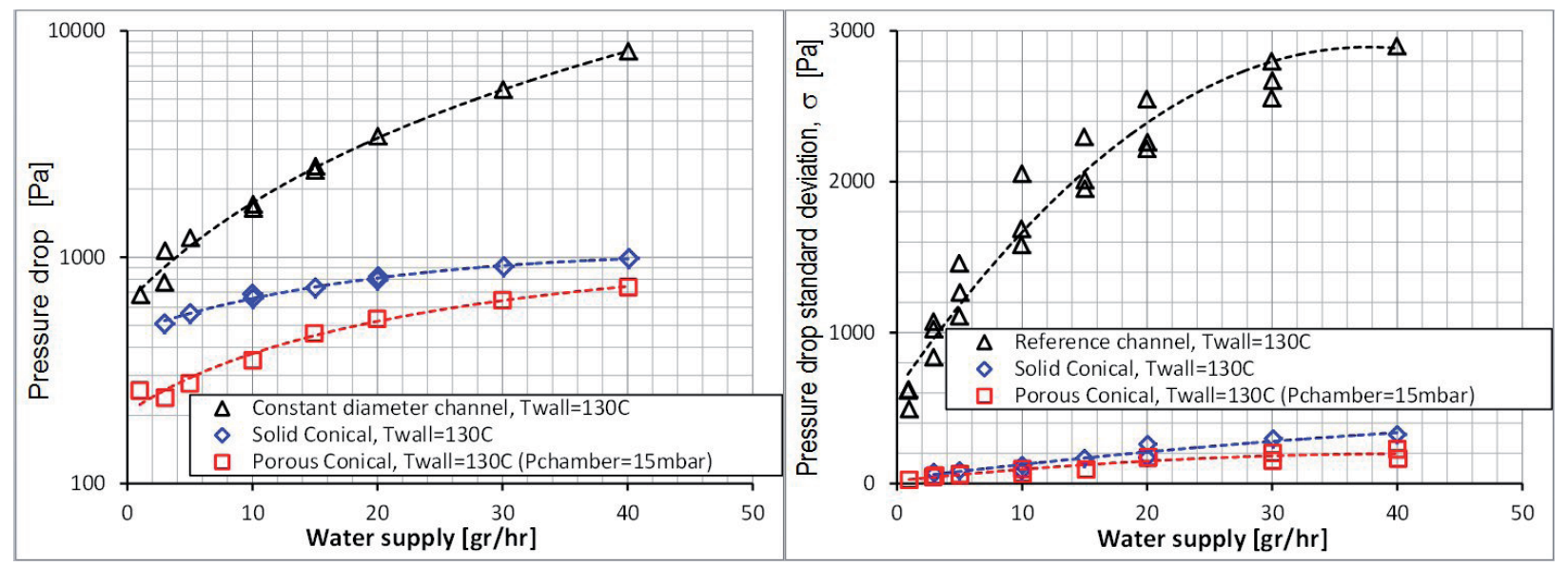

FIG. 2: Total pressure drop comparison (left) and comparison of the pressure drop fluctuations by means of standard deviation (right).

Altering the channel geometry from a constant diameter channel to a conical channel reduces the total pressure drop by a factor of 2 at low flow rates and up to a factor of 8 at high flow rates (Fig. 2, left). This corresponds to the values predicted for conical channels with a diameter ratio, Eq. (3). The porous wall conical channel appears to reduce the pressure drop again by a factor of 2 to 1.5 with respect to the solid conical channel. However, Fig. 2 shows that all curves have a certain offset at zero mass flow rate. The zero-flow offset is most likely caused by water-air interfaces present near the small tube of the pressure sensor. If these zero-flow offsets are subtracted, the solid and porous conical measurements are not all that different. However, the pressure fluctuations, quantified by the standard deviation of the measured pressure drop time signal, of the porous conical channel are less by $30 \%$ to $40 \%$ than those of the solid conical channel (Fig. 2, right).

The two rows of five thermocouples allow estimation of the heat flux and the temperature profile in the wall. The resulting wall temperatures at five axial positions along the channel are given in Fig. 3.

The wall temperature profiles of the solid channels are all similar. The porous conical channel show elevated temperatures compared to the solid conical channel. The gas temperature on entry of the pressurized chamber is about room temperature. However, on passing through the thick porous wall the nitrogen is heated toward the wall temperature. It is estimated from residence times and effective heat transfer coefficients that for the applied nitrogen flow rates the wall thickness is sufficient to fully heat up the nitrogen.
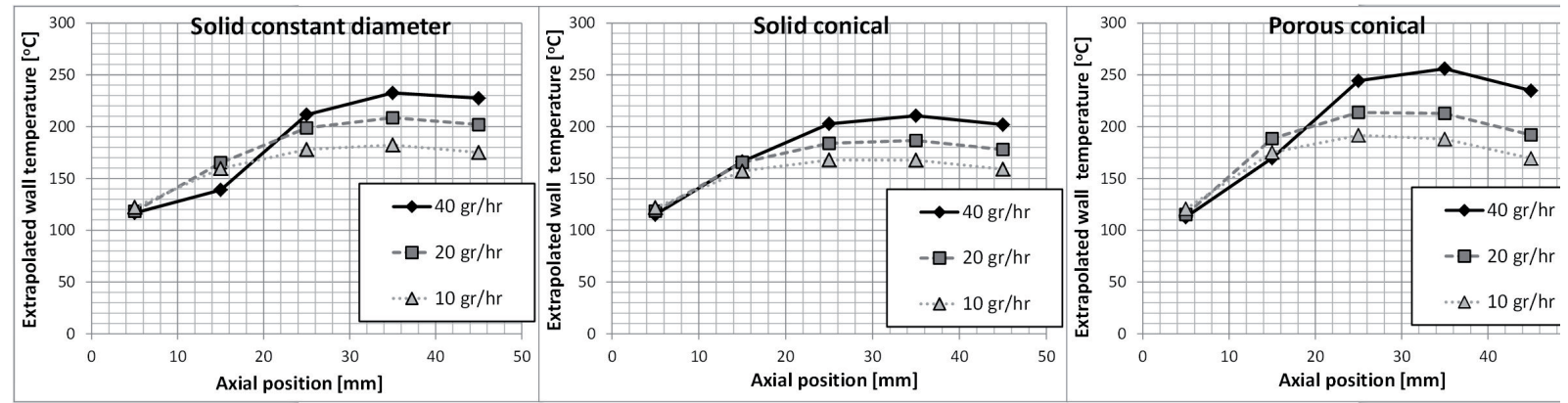

FIG. 3: Extrapolated wall temperatures for 10,20 , and $40 \mathrm{~g} / \mathrm{hr}$ mass flow rate. Left: Constant diameter channel, $0.6 \mathrm{~mm}$. Middle: Solid conical channel, 0.6-3 mm. Right: Porous conical channel, 0.6-3 mm. 


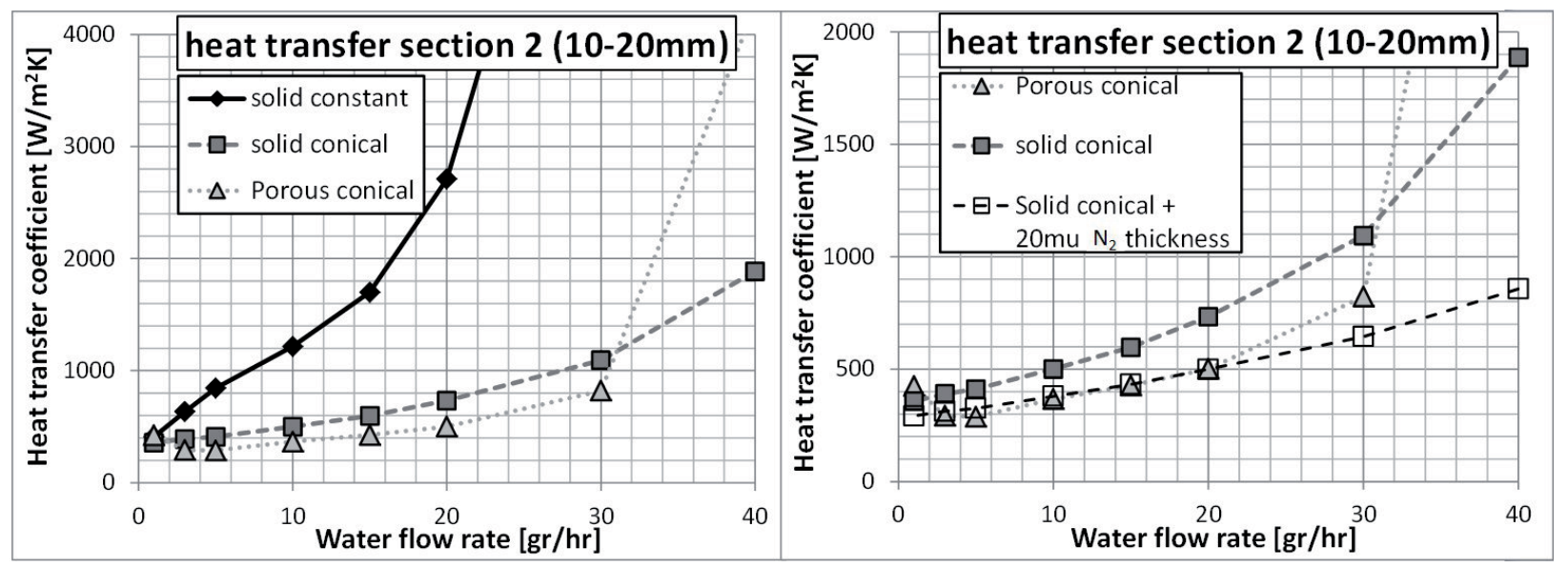

FIG. 4: Comparison of estimated heat transfer coefficients of the second section of the channel. The open rectangles on the right are computed in a way explained in the text.

The heat transfer coefficient along the channel has been defined as the ratio of the heat flux to the difference in wall temperature and saturation temperature at the prevailing system pressure. The heat transfer coefficient has been estimated in the second section of the channel, 10-20 mm axially downstream of the inlet (Fig. 4, left). Due to the thick wall the lateral conduction through the wall, in axial direction, can amount to about $20 \%$ of the radial heat flux, maximum. The one-dimensional heat transfer model is therefore appropriate as a first-order approximation. In one sample case, a heat resistance equivalent to a $20 \mu \mathrm{m}$ thick nitrogen layer has been added to the heat transfer resistance of the solid conical channel, for comparison. The heat transfer coefficients of this adapted solid conical and of the porous conical channels coincide for flow rates up to $30 \mathrm{gr} / \mathrm{h}$ (Fig. 4, right). For the higher water flow rate the nitrogen injection is most likely not capable to lift the water from the wall near the inlet. However, hot gas keeps on entering the flow channel also at these higher flow rates, and by doing so the hot gas enhances the mixing in the liquid near the wall. The enhanced mixing directly increases the heat transfer from the wall to the liquid. For the other channel sections such an additional resistance has not been found. This is easily understood for the downstream sections from high volume fractions of vapor there. For the first section of $10 \mathrm{~mm}$ channel length, a possible explanation for not observing this additional resistance is boundary layer development.

\section{CONCLUSIONS}

Pressure drop histories have been measured in a straight channel, a conical channel, and a conical channel with a porous wall through which hot nitrogen flows. A considerable reduction of mean pressure drop and fluctuation level is found. In the case of the porous wall the results can be explained with a gas film residing at the wall.

Wall temperatures and heat fluxes have been measured in five axial sections of the evaporator. The decrease in heat transfer coefficient in the second section is found to be equivalent to a gas layer with a thickness of around $20 \mu \mathrm{m}$. Future research will be focused at the formation and the stability of a gas layer at the wall using a setup allowing for optical access.

\section{REFERENCES}

Huh, D., Kuo, C. H., Grottberg, J. B., and Takayama, S., Gas-liquid two-phase flowpatterns in rectangular microchannels: Effect of surface wetting properties, New J. Phys., vol. 11, pp. 1-14, 2009.

Kandlikar, S. G., Heat transfer mechanisms during flow boiling in microchannels, J. Heat Transfer, vol. 126, pp. 8-16, 2004. 
Kennedy, J. E., Roach Jr., G. M., Dowling, M. F., Abdel-Khalik, S. I., Ghiaasiaan, S. M., Jeter, S. M., and Quershi, Z. H., The onset of flow instability in uniformly heated horizontal microchannels, J. Heat Transfer, vol. 122, no. 1, pp. 118-125, 2000.

Mori, S. and Okuyama, K., Enhancement of the critical heat flux in saturated pool boiling using honeycomb porous media, Int. $J$. Multiphase Flow, vol. 35, no. 10, pp. 946-951, 2009.

Mukherjee, A. and Kandlikar, S. G., Numerical study of the effect of inlet constrain on bubble growth during flow boiling in micro channels, in Proc. of 3rd Intl. Conf. on Micro and Minichannels, Toronto, Canada, 2005.

Nakayama, W., Daikoku, T., and Nakajima, T., Effects of pore diameters and system pressure on saturated pool nucleate boiling heat transfer from porous surfaces, J. Heat Transfer, vol. 104, no. 2, pp. 286-292, 1982.

Nakla, M. E., Groeneveld, D. C., and Cheng, S. C., Experimental study of inverted annular film boiling in a vertical tube cooled by R-134a, Int. J. Multiphase Flow, vol. 37, no. 1, pp. 67-75, 2011.

Perry, J. F., Fouling in Silicon Microchannel Designs Used For ic Chip Cooling and its Mitigation, PhD Thesis, Rochester Institute of Technology, 2008.

Ramesh, P. S., Torrance, K. E., Stability of boiling in porous media, Int. J. Heat Mass Transfer, vol. 33, no. 9, pp. 1895-1908, 1990.

Ramesh, P. S. and Torrance, K. E., Boiling in a porous layer heated from below: Effects of natural convection and a moving liquid/two-phase interface, J. Fluid Mech., vol. 257, pp. 289-309, 1993.

Rops, C. M., Geers, L. F. G., and Westerweel, J., Explosive bubble growth during flow boiling in micro-channels, in Proc. of 5th European Thermal-Sciences Conf., Eindhoven, The Netherlands, 2008.

Rops, C. M., Oosterbaan, G. J., and v.d. Geld, C. W. M., A way to reduce the pressure drop in once-through micro evaporators, Exp. Heat Transfer, vol. 27, no. 4, pp. 329-339, 2014.

Sahli, A., Moyne, C., and Stemmelen, D., Boiling stability in a porous medium heated from below, Transp. Porous Media, vol. 82, no. 3, pp. 527-545, 2010.

Shagapov, V. Sh. and Nurislamov, O. R., The flow of liquid past a plate with boiling and injection of gas, Heat Mass Transfer Phys. Gasdynamics, vol. 48, no. 4, pp. 555-564, 2010.

Stemmelen, D., Moyne, C., and Degiovanni, A., Unstable boiling state in a porous medium, Inst. Chem. Eng. Symp. Ser., vol. 2 , no. 129, pp. 1131-1137, 1992.

Takamasa, T., Hazuku, T., and Hibiki, T., Experimental study of gas-liquid two-phase flow affected by wall surface wettability, Int. J. Heat Fluid Flow, vol. 29, no. 6, pp. 1593-1602, 2008.

Yan, J. H., Laker, T. S., and Ghiaasiaan, S. M., Linear stability of inverted annular gas-liquid two-phase flow in capillaries, Int. J. Heat Fluid Flow, vol. 24, no. 1, pp. 122-129, 2003.

Zhang, L., Wang, E. N., Goodson, K. E., and Kenny, T. W., Phase change phenomena in silicon microchannels, Int. J. Heat Mass Transfer, vol. 48, pp. 1572-1582, 2005. 